\title{
Bombax ceiba: A Potential Anti-Anxiety Drug
}

\author{
Abdulrahman Alsayari, Mohammed Ghazwani, Dalia Almaghaslah, Yahya Alhamhoom, MahaSaad, \\ Rawan Ahmed, Wafa Saeed, Wijden Ali, Sadia Batool*
}

\section{Abdulrahman Alsayari, Mohammed Ghazwani, Dalia Almaghaslah, Yahya Alhamhoom, Maha Saad, Rawan Ahmed, Wafa Saeed, Wi- jden Ali, Sadia Batool ${ }^{*}$}

College of Pharmacy, King Khalid University, Abha, KINGDOM OF SAUDIA ARABIA.

\section{Correspondence}

Dr. Sadia Batool

Department of Pharmacology, College of Pharmacy, King Khalid University, Kingdom of Saudia Arabia.

Phone no : 0966-557316186

E-mail: sadiabatoolkku@gmail.com

History

- Submission Date: 05-02-2018;

- Review completed: 15-03-2018;

- Accepted Date: 19-04-2018

DOI : 10.5530/pj.2018.4.118

Article Available online

http://www.phcogj.com/v10/i4

\section{Copyright}

(C) 2018 Phcog.Net. This is an openaccess article distributed under the terms of the Creative Commons Attribution 4.0 International license.

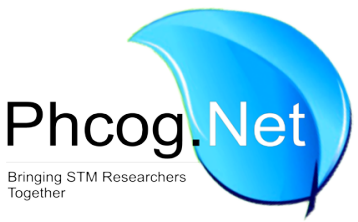

ABSTRACT

Background: Bombax ceiba is a famous plant used extensively in traditional medicine for various diseases. However, data pertaining to its effects at CNS level is limited. Objective: To analyze the anti-anxiety potential of ethanolic extracts of Bombax ceiba leaves on rats using the elevated plus maze protocol. Materials and Methods: Five groups containing six rats each were treated with respective drugs. Control rats were treated with $0.5 \mathrm{ml}$ of $10 \%$ ethanol i.p. (negative control). Single treatments of diazepam ( $2 \mathrm{mg} / \mathrm{kg}$ i.p) were used as a positive control and varied levels of ethanolic extracts of Bombax ceiba leaves $(150 \mathrm{mg} / \mathrm{kg}, 250 \mathrm{mg} / \mathrm{kg}$, $400 \mathrm{mg} / \mathrm{kg}$, i.p.) were applied to other groups. The index of anxiety was measured by observing the entry and time duration in the open arm of the EPM. Results: Extract at $400 \mathrm{mg} / \mathrm{kg}$ significantly increased the time duration and number of entries into the open arm which was statistically significant ( $p$ value $<0.05$ ) when compared to the control group (ethanol). Diazepam showed the most significant results when compared to other groups $(p<0.0005)$. Extracts at $150 \mathrm{mg} / \mathrm{kg}$ and $250 \mathrm{mg} / \mathrm{kg}$ demonstrated negligible results that were statistically insignificant. Conclusion: The results indicate the anti-anxiety potential of Bombax ceiba leaves at higher concentration. Further studies are required to analyze the implicated phytochemicals and the mechanism at cellular level.

Key words: Anti-anxiety, Bombax ceiba leaves, Diazepam, Ethanol, Elevated plus maze.

\section{INTRODUCTION}

Psychological diseases are very common nowadays, with an increasing incidence. ${ }^{1}$ A 2009 WHO survey indicated that mood disorders and anxiety were the most common mental health problems around the world. ${ }^{1}$ Epidemiological studies have shown that one third of the population is affected with anxiety disorders at least once in their lifetime. These disorders may create diminishment of life and a financial burden along with health care costs.

Anxiety is usually treated with the sedative hypnotic group of drugs. The benzodiazepine group of drugs are generally prescribed but carry the burden of low safety margin and dependency. ${ }^{2,3}$ Of the newer groups, partial agonist at serotonin receptors have gained wide acceptance. These drugs, however, take up to 4 weeks to show effect and are quite costly as well. ${ }^{4}$ Some patients are generally resistant to these drugs and have limited response to treatment.

On the other hand, traditional healing with plants and their extracts has been used for treating mental disorders since many years. Some famous plants are Hypericum perforatum and Nigella sativa for depression., Passiflora and Chamomile for anxiety disorders. ${ }^{7,8}$ The effects are due to certain phytochemical constituents in these plants.
Bombax ceiba is a tree from the Malvaceae family which grows in Indonesia, Malaysia, China, Hong Kong and Taiwan. The tree has red blossoms with five petals. Tibetans refer to it as "salmari", while in Europe and America, it is ordinarily referred as the cotton tree. It is utilized as a tea in parts of China.

This tree is rich in various phytochemicals. Extracts have confirmed the presence of alkaloids, flavonoids, glycosides, coumarins, proteins and amino acids. ${ }^{9}$ Bombax ceiba has numerous documented effects, some of which are anti-inflammatory, aphrodisiac, antimicrobial, hepatoprotective, anti-diabetic, antiaging and hypotensive. ${ }^{10-16}$ Evaluation at the CNS level, however, is limited. Therefore our study is aimed at analyzing the anti-anxiety potential of this plant analyzing the anti-anxiety potential of this plant.

\section{MATERIALS AND METHODS}

\section{Plant material}

Bombax ceiba leaves were washed with water and shade dried. After crushing into a powder, $100 \mathrm{gm}$ was placed in $500 \mathrm{ml}$ of $70 \%$ ethanol in a dark place for three days with frequent agitation. The obtained extract was then filtered and dried with a rotary evaporator. 


\section{Animals and grouping}

The experiments were performed according to university guidelines as per the research committee and ethical committee approval. The subjects consisted of 30 albino rats, 125-150 gm in weight and of both genders. These were obtained from the animal house at the College of Pharmacy, King Khalid University, Saudi Arabia. The animals were allowed free access to water and food ad libitum. They were kept in normal temperatures with a 12-h light dark cycle. The animal experiments were carried out as per the National Institutes of Health guide for the care and use of Laboratory animals.

Five groups of six rats each were formed and treated with their respective test drugs, as follows:

- Group I: Positive control, Diazepam $2 \mathrm{mg} / \mathrm{kg}, \mathrm{n}=6$

- Group II:Vehicle control, *Ethanol $10 \%(0.5 \mathrm{ml}), \mathrm{n}=6$

- Group III:Bombax ceiba extract, $150 \mathrm{mg} / \mathrm{kg}, \mathrm{n}=6$

- Group IV: Bombax ceiba extract, $250 \mathrm{mg} / \mathrm{kg}, \mathrm{n}=6$

- Group V: Bombax ceiba extract, $400 \mathrm{mg} / \mathrm{kg}, \mathrm{n}=6$

*(Absolute ethanol, HolyLandPharma, Makkah, Saudi Arabia) All extracts were diluted with $0.5 \mathrm{ml}$ of ethanol each for application.

\section{Elevated Plus Maze}

The elevated plus maze (EPM) is a plus shaped apparatus which has been used in neurobiological research. It has two open arms and two closed arms placed in a plus shape at a height of $50 \mathrm{~cm}$. Rats prefer to stay in closed areas when in anxiety, a reduction in anxiety is observed by the entry of the animal into the open arm of the maze. ${ }^{17}$ Behavioral responses in the elevated plus maze are easily assessed and quantified by an observer. Briefly, rodents are placed in the center intersection of the four arms of the elevated plus maze and their behavior is typically recorded for 5 min. ${ }^{18}$

\section{Experimental Protocol}

Dried extracts were diluted with $10 \%$ ethanol, $0.5 \mathrm{ml}$ each. ${ }^{19}$ Each animal was subjected to its respective drug through intra-peritoneal injection. Each animal was placed individually in the center of the maze and observed for $5 \mathrm{~min}$. The number of entries and the time duration spent in the open arm were noted during this period. When the animal placed all four paws in the open arm, it was calculated as one entry. The observations were noted for each animal and the results were analyzed.

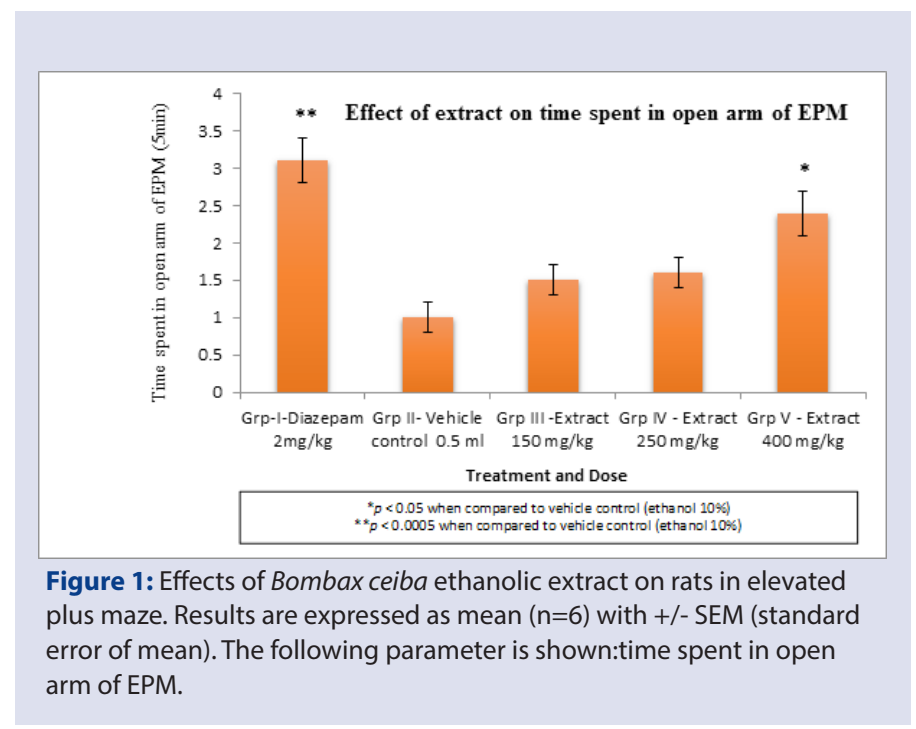

\section{Statistical analysis}

The mean of each group was calculated and compared through graphs for the two parameters, time spent in the open arm and duration spent in the open arm of the EPM.

The $\mathrm{P}$ value was calculated by one-way analysis of variance ANOVA followed by a Dunnet test. The P values $<0.05$ were considered statistically significant when compared to the vehicle control.

\section{RESULTS}

In the present study, we used the elevated plus maze to analyze the antianxiety effects of ethanolic extract of Bombax ceiba leaves. The EPM model uses the rat's natural fear and aversion of open and elevated places to determine anxiety levels. The number of entries into the open arm of the EPM and the time spent in it is used as an index of the anti-anxiety effect.

The time spent in the open arm of EPM was calculated over 5 min for each animal. Rats tend to stay in closed spaces when feeling fear or apprehension, therefore movement into the open arm of EPM depicts the animals less anxious state. Diazepam treated animals exhibited the least anxiety and preferred to stay and enter in the open arm of the EPM ( $p$ value $<0.0005$ when compared to vehicle control). Animals treated with extracts at $250 \mathrm{mg} / \mathrm{kg}$ and $400 \mathrm{mg} / \mathrm{kg}$ showed increased time spent in the open arm of the EPM (Figure 1). For the $400 \mathrm{mg}$ extract time spent in open arm when compared to vehicle control (ethanol) yielded $\mathrm{p}$ values of $<0.05$ which was statistically significant (Figure 1). The values were not significant for animals treated with $250 \mathrm{mg} / \mathrm{kg}$ and $150 \mathrm{mg} / \mathrm{kg}$ of extract.

The number of entries of each rat into the open arm was also calculated over $5 \mathrm{~min}$. The reading was noted as one when the whole paw of the animal entered the open arm. Entry into the open arm is depicted as an anti-anxiety behavior of the animal. Again, diazepam treated animals exhibited the highest anti-anxiety effect due to increased entry into the open arm of the EPM ( $p$ value $<0.0005$ when compared to vehicle control) (Figure 2). The results were also statistically significant for the 400 $\mathrm{mg} / \mathrm{kg}$ extract ( $\mathrm{p}$ value $<0.05$ when compared to vehicle control), while less anti-anxiety effects were observed for the $150 \mathrm{mg} / \mathrm{kg}$ and $250 \mathrm{mg} / \mathrm{kg}$ extract with statistically insignificant readings (Figure 2).

\section{DISCUSSION}

Our study has confirmed the anti-anxiety potential of ethanolic extract of Bombax ceiba leaves. The elevated plus maze was used in this experi-

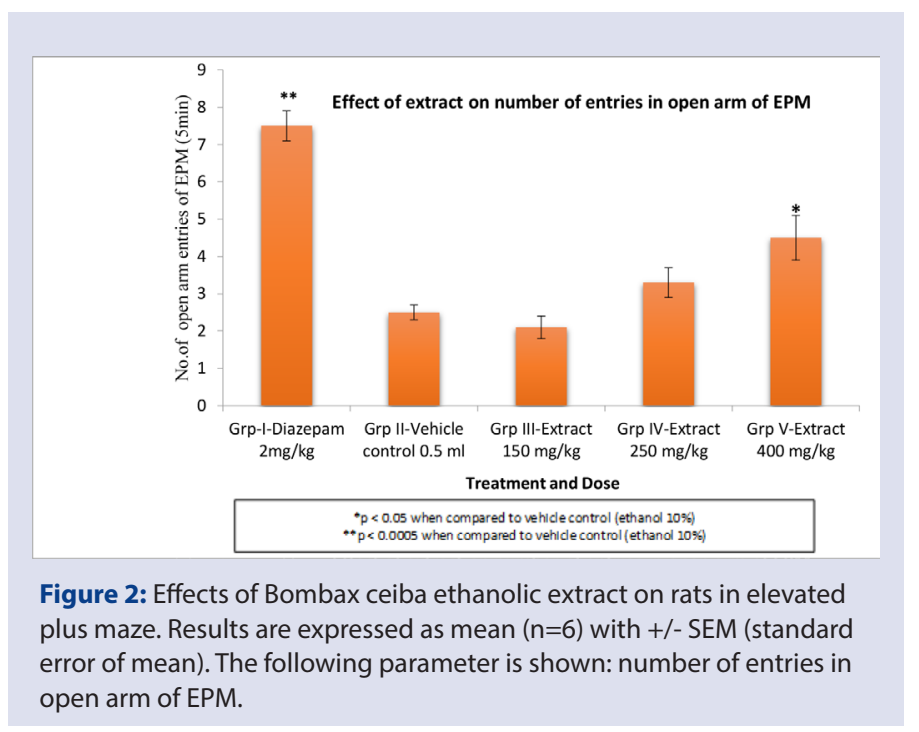


ment. The elevated plus maze is a widely used behavioural assay for anxiety behaviour of rodents. It is easy to use and yields valid results in a short 5-min test period. The patterns of results obtained using this task are replicable across other species, anxiety/affective behaviour measures, studies and laboratories.

Bombax ceiba is a common traditional medicine plant, which is a rich source of many phytochemicals, including triterpenes/ triterpenoids, flavonoids, anthocyanin, shaminicin, vicenin, scopolin, mangifein and vitexin. ${ }^{20}$ Lately, two new phytochemicals have been derived, simalin A and B. ${ }^{21}$

The phytochemicals like flavonoids, triterpenoids and lupeol in this plant may be the cause of its anti-anxiety effects. Various plants with similar phytochemicals have shown anti-anxiety effects. Triterpenoids have documented effects at central nervous level, particularly anti-anxiety potential. ${ }^{22}$ One of the triterpenoids, lupeol, has been proven to provide anxiety-reducing effects. ${ }^{22}$ Flavonoids have calming effects as well. Apigenin, a flavonoid constituent of the plant Matricaria chamomile, acts as a ligand for benzodiazepine receptors in the CNS, causing sedative hypnotic effects. ${ }^{23}$ Our plant exhibits phytochemicals such as flavonoids and triterpenoids, which could be reason for CNS calming effects.

There is extensive data on the use of herbs and plants for sedative actions. A famous herb, Valerian is extensively used for its anti-anxiety and sleep-enhancing properties. In rat brainstem experiments; the effects of this herb were shown to be mediated by actions at the central GABA receptors. ${ }^{24} \mathrm{Kava}$ is a drink derived from thePiper methysticum plant. It is used extensively for its CNS calming effects. Extracts from this plant have been shown to bind to central receptors linked to GABA, dopamine and opiates. ${ }^{25,26}$

Our study has provided yet another addition to these alternative therapies for anxiety. The implicated phytochemicals and the mechanism at the cellular level have to be determined. Also the toxicological screen and effective dose have to be evaluated. The conventional drugs in market have various adverse effects, mainly addiction and tolerance, this plant can provide an alternative and safer therapy for anxiety.

\section{CONCLUSION}

This study confirms the anti-anxiety potential of Bombax ceiba leaves. The results have indicated an anxiety lowering effect using a $400 \mathrm{mg} / \mathrm{kg}$ extract when administered through the intra-peritoneal route. This provides us with a potential new alternative therapy for treating anxiety disorders

\section{ACKNOWLEDGEMENT}

We would like to thank the Deanship of research, King Khalid University, for providing us with the facilities and funds to carry out this research

\section{ABBREVIATIONS}

EPM: Elevated Plus Maze; CNS: Central Nervous System; GABA: Gaba ammino butyric acid.

\section{CONFLICT OF INTEREST}

There are no conflicts of interest.

\section{SUMMARY}

Bombax ceiba is a famous plant used in traditional medicine. It is rich in phytochemicals and has various uses. Studies at CNS level are lacking, therefore this research was carried out to evaluate any anti-anxiety potential of its leaves. Ethanolic extract at $400 \mathrm{mg} / \mathrm{kg}$ demonstrated antianxiety effects in animals by increasing time duration and entry in open arm of EPM. This was statistically significant $(p<0.05)$ when compared to vehicle control. Our study therefore proposes a potential new addition in treating anxiety disorder.

\section{REFERENCES}

1. Kessler RC, Aguilar-Gaxiola S, Alonso J, Chatterij S, Lee S, Ormel J, et al. The global burden of mental disorders: An update from the WHO World Mental Health (WMH) Surveys. EpidemiologiaePsichiatriaSociale. 2009;18(1):23-33.

2. Milos $V$, Bondesson $\AA$, Magnusson $M$, Jakobsson $U$, Westerlund T, Midlöv P. Fall risk-increasing drugs and falls: a cross-sectional study among elderly patients in primary care. BMC Geriatrics. 2014;14(1):40.

3. Hallström C, ed. Benzodiazepine dependence. Oxford: Oxford University Press. 1993.

4. Gorman JM. Treatment of generalized anxiety disorder. J Clin Psychiatry. 2002;63(Suppl8):17-23.

5. Tian J, Zhang F, Cheng J, Guo S, Liu P, Wang H. Antidepressant-like activity of adhyperforin, a novel constituent of Hypericumperforatum L. Scientific Reports 2014:4(1):5632

6. Perveen T. Increased 5-HT Levels Following Repeated Administration of Nigella sativa L. (Black Seed) Oil Produce Antidepressant Effects in Rats. ScientiaPharmaceutica. 2013:82(1):161-70.

7. Amsterdam JD, et al. A Randomized double blin placebo controlled trial of oral Matricariarecutita (chamomile) extract therapy for generalized anxiety disorder. Journal of Clinical psychophamacology. 2009;29(4):378-82.

8. Dhawan K, Kumar S, Sharma A. Evaluation of Central Nervous System Effects of Passifloraincarnata in Experimental Animals. Pharmaceutical Biology. 2003;41(2):87-91.

9. Chakraborty D, Ravi V, Chakraborty P. Phytochemical evaluation and TLC protocol of various extracts of Bombaxceiba Linn. IJPSR. 2010;1(8):63-71.

10. Wanjari MM, Gangoria R, Dey YN, Gaidhani SN, Pandey NK, Jadhav AD. Hepatoprotective and antioxidant activity of Bombaxceiba flowers against carbon tetrachloride-induced hepatotoxicity in rats. Hepatoma Research. 2016;2(6):144

11. Patil PS, Patel MM, Bhavsar CJ.ComparatativeAntidiabetic activity of some herbal plan extracts. Pharma Science Monitor. 2010;1(1):12-9.

12. Saleem R, Ahmad SI, Ahmed M, Faizi Z, Zikr-Ur-Rehman S, Ali M, et al. Hypotensive Activity and Toxicology of Constituents from Bombaxceiba Stem Bark. Biological and Pharmaceutical Bulletin. 2003;26(1):41-6.

13. Jagtap A, Shirke S, Phadke A. Effect of polyherbal formulation on experimental models of inflammatory bowel diseases. Journal of Ethnopharmacology. 2004;90(2-3):195-204

14. Ngwuluka NC. Are Bombaxbuonopozense and Bombaxmalabaricumpossible nutraceuticals for age management? Preventive Medicine. 2012;54:S64-70.

15. Wang YC, Huang TL. Screening of anti-Helicobacter pyloriherbs deriving from Taiwanese folk medicinal plants.FEMS Immunology and Medical Microbiology. 2005:43(2):295-300

16. Bhargava C, Thakur M, Yadav.Effect of Bombaxceiba L. On spermatogenesis, sexual behaviour and erectile function in male rats. Andrologia. 2012:44(s1):474-8.

17. Pellow S, Chopin P, File SE, Briley M. Validation of open: Closed arm entries in an elevated plus-maze as a measure of anxiety in the rat. Journal of Neuroscience Methods. 1985;14(3):149-67.

18. Montgomery KC. The relation between fear induced by novel stimulation and exploratory drive.Journal of Comparative and Physiological Psychology. 1955;48(4):254-60.

19. Obregon AD et al. Effects per se of organic solvents in the cerebral acetylcholinesterase of rats. Neurochemical Research. 2005;30(3):379-84.

20. Bombacaceae: A phytochemical review. Pharmaceutical Biology. 2013;51(1):100-30

21. Joshi KR, Devkota HP, Yahara S, Simalin AB: Two new aromatic compounds from the stem bark of Bombaxceiba. Phytochemistry Letters. 2014;7:26-9.

22. Parkar SK, et al. Neuropharmacological effects of triterpenoids. Phytopharmacology. 2013;4(4):354-72.

23. Avallone $R$, et al. Pharmacological profile of apigenin, a flavonoid isolated from matricariachamomilla. BiochemPharmacol. 2000;59(11):1387-94.

24. Yuan CS, Mehendale S, Xiao Y, Aung HH, Xie JT, Ang-Lee MK. The GammaAminobutyricAcidergic Effects of Valerian and Valerenic Acid on Rat Brainstem Neuronal Activity.Anesthesia and Analgesia. 2004;98(2):353-8.

25. Dinh LD, Simmen U, Bueter KB, Bueter B, Lundstrom K, Schaffner W. Interaction of Various Piper methysticum Cultivars with CNS Receptors in vitro. PlantaMedica. 2001;67(4):306-11.

26. Yuan CS, Dey L, Wang A, Mehendale S, Xie JT, Aung HH, et al. Kavalactones and Dihydrokavain Modulate GABAergic Activity in a Rat Gastric-Brainstem Preparation. PlantaMedica. 2002;68(12):1092-6.

27. Walf AA, Frye CA. "The Use of the Elevated plus Maze as an Assay of AnxietyRelated Behavior in Rodents." Nature Protocols. 2007;2(2):322. 